\title{
Para una propuesta de análisis del discurso de los derechos humanos en la prensa escrita durante el zedillismo
}

Tanius Karam ${ }^{1}$

\section{Introducción}

La idea moderna de los derechos humanos (en adelante, $\mathrm{DH}$ ) suele remontarse a la Declaración de los Derechos del Hombre y el Ciudadano (1789) y a la Declaración de Virginia (1776). Autores como el filósofo mexicano Mauricio Beuchot sugieren que este "origen" no es preciso, ya que es posible encontrar en el mundo occidental sistemas de defensas de los derechos de las personas anteriores a las Declaraciones, como fue el caso de la Escuela de Salamanca (siglo XVI), de la que emergerían para defender los derechos de los indios Tomas de Vitoria y Bartolomé de las Casas. Cualquier origen que quiera precisarse debe considerar los DH como una noción compleja, vinculada no sólo a cuestiones jurídicas o filosóficas sino a nociones del mundo, la sociedad, que han dado sentido a las luchas sociales y la búsqueda de mejores condiciones de vida.

En cuanto a la historia de los DH en el México posrevolucionario, por muchos años se negó su existencia. Cuando no quedó más remedio reconocer su existencia, se mencionó que los casos de violaciones eran aislados y que no reflejaban para nada la situación del país. La historia del discurso público de DH hay que buscarla en la nota roja, y en la presencia en la información nacional de las organizaciones de los perseguidos políticos y de las organizaciones civiles de $\mathrm{DH}$.

Nuestra reflexión en este escrito tiene como antecedente un estudio sobre la prensa escrita mexicana a propósito de los dos principales casos violatorios

1. ITESM campus Ciudad de México. Universidad de la Ciudad de México. Correo electrónico: tanius@yahoo.com. 
de DH durante el sexenio del presidente Ernesto Zedillo (1994-2000): la matanza de Aguas Blancas (AB), ocurrida en el vado del mismo nombre en la sierra de Atoyac, en Guerrero (28 de junio 1995), y la matanza en la aldea de Acteal, municipio de Chenalhó, en Chiapas (22 de diciembre de 1997). En estas líneas haremos algunos comentarios a las noticias generadoras del caso Aguas Blancas aparecidas en tres diarios como referencia dominante ( $L a$ Jornada, Reforma, El Universal) (Imbert y Beneyto, 1986).

Después de caracterizar el metarrelato (MR) informativo de DH, pasaremos a describir algunos niveles de sentido en la construcción del relato de prensa sobre el caso Aguas Blancas.

\section{El discurso de los derechos humanos}

El discurso se ha convertido en un término que traspasa fronteras disciplinarias. No es reducible a un ámbito específico, y su alusión puede servir para explicar fenómenos sumamente amplios. La palabra discurso suele ser entendida como "texto". Genéricamente se establecen algunas diferencias entre el "texto" como "la manifestación concreta del discurso", "el producto en sí" y el "discurso", que se entiende como "todo el proceso de producción lingüística que se pone en juego para producir algo" (Giménez, 1983: 125; Lozano, Peña Marín y Abril 1997: 15-16). Un repaso a varios textos sobre análisis del discurso (Gutiérrez, 1988; Haidar, 1998; Abril, 1995) nos permite identificar campos de condensación en la producción teórica y metodológica del discurso: la aproximación formalista (intra-discursiva) que ve al discurso como fuente de sí mismo, sea que se trate de frases o enunciados, o bien de relatos o macro-estructuras; la orientación enunciativa (Benveniste, Jakobson) que considera al discurso como parte de un modelo de comunicación, y la perspectiva materialista del discurso de Pecheux y Robin, la cual entiende al discurso como una práctica social vinculada a sus condiciones sociales de producción, así como a su marco de producción institucional, ideológica cultural e histórico-coyuntural (Gutiérrez, 1988: 79-82).

El discurso es una realidad compleja que implica nociones lingüísticas, semánticas, pragmáticas, cognitivas y culturales. En nuestra caracterización del discurso resaltamos algunos aspectos: a) el rasgo enunciativo, en tanto que todo discurso da cuenta del proceso de comunicación en el que se inserta; el discurso es de suyo un proceso interactivo en el que no sólo es posible seguir - de acuerdo a las teorías de la enunciación - las huellas del destinador, sino también aquellas que le pertenecen al destinatario; b) el rasgo retórico y argumental, en tanto movilizador de una serie de procesos que llevan el sentido de producir determinados efectos; el discurso como un texto dirigido 
a un enunciatario, en el caso de las noticias que analizaremos para hacer-creer el dispositivo desplegado en el texto noticioso; ${ }^{2}$ c) el rasgo dramatúrgico de todo discurso como "puesta en escena" que se verifica mediante la organización y jerarquización de la información.

El criminólogo Stanley Cohen (1998) ha descrito los contextos enunciativos en los que se produce, distribuye y consume el discurso público de los DH: el ámbito diplomático, jurídico-legal (el académico, el profesional, el constitucional), el asociativo e institucional (de observación, monitoreo e intervención), el científico-social, el educativo, el político. Un estudio integral sobre los DH daría cuenta de cómo los diferentes discursos -en sus formas de decir, actuar, de interactuar y relacionarse, de persuadir y mover al destinatarioestán constituidos por ciertos tipos de presuposiciones y asunciones, de actos de habla y usos del lenguaje. A estos contexto enunciativos sugeridos por Cohen nosotros añadimos el discurso periodístico de DH que, de alguna forma, integra y sintetiza los anteriores, y puede, en sus fuentes enunciadoras, recurrir a todos los actores sociales que producen información y saber en el ámbito de los $\mathrm{DH}$.

\section{Dimensión narrativa del discurso periodístico de DH}

Si tomamos en cuenta una definición estándar de lo que es un relato (Prieto, 1986: 175-176), consideramos a éste un texto referencial en el que se presenta un cierto transcurso temporal y una secuencia o serie de acciones en la que se observan dos atributos de un agente; el relato consiste en la transformación de un atributo al otro. Para subrayar esta dimensión del discurso noticioso sugerimos una aproximación diacrónica, que considera la evolución de una historia o un tema a lo largo de una secuencia que ha sido disparada por una noticia generadora (en nuestro caso, la matanza de Aguas Blancas). La noticia es un relato susceptible de estudiarse de acuerdo a modelos narratológicos o herramientas de la semiótica narrativa. Uno de estos instrumentos es el modelo actancial greimasiano, que resumimos a continuación.

2. El análisis del discurso ha desarrollado variadas metodologías con una perspectiva argumental; desde la topografía y esquematización de los argumentos en Vignaux y las orientaciones estructurales de Toulmin, hasta la esquematización argumental de J. B. Grize o la semántica argumental de Ducrot. Compartimos la idea de que la dimensión argumental del discurso no es exclusiva de ciertos discursos y podemos encontrar procedimientos persuasivos aun en discursos cuya función primaria no es la persuasión o la incitación; la argumentación no es una característica de algunos discursos, sino un nivel discursivo. 


\section{Variaciones y tema de la semiótica greimasiana}

Las bases del modelo actancial greimasiano hay que buscarlas en La morfología del cuento ruso (1928) de Vladimir Propp, quien permitió una comprensión distinta de cómo se organizan los componentes de un texto para significar. Propp inspiró buena parte de los análisis de Lévi-Strauss sobre el mito, sirvió para construir los primeros esbozos de la sintaxis narrativa y la lógica del relato.

Propp encuentra un repertorio delimitado de siete personas -en tanto que eventuales ejecutantes de esas funciones-: el agresor, el donante, el auxiliar mágico, el mandatario, el héroe, el falso héroe, la princesa (u objeto de búsqueda). Los modelos narrativos, como el de Propp, nos permiten identificar actores, escenas, pero sobre todo funciones y esferas de acción (cada personaje es una esfera, una esfera para varios personajes, un personaje en varias esferas).

En el modelo, Greimas incluye cuatro actantes básicos, incluidos ya en el eje de la comunicación y del deseo (o búsqueda). Actantes a los que se añaden dos circunstantes en el eje de la prueba: ayudante (auxiliar) versus oponente (opositor). Una tercera pareja es el destinador versus destinatario (A4) unidos entre sí por la transmisión y la comunicación de un objeto.

Con base en lo anterior, hemos encontrado que es pertinente una primera descripción del MR informativo de $\mathrm{DH}$ a partir de las categorías del esquema actancial greimasiano.

\begin{tabular}{|l|l|l|l|l|l|l|}
\hline Tipo de relato & Sujeto & Objeto & Destinador & Destinatario & Adyuvante & Oponente \\
\hline $\begin{array}{l}\text { Discurso } \\
\text { periodístico } \\
\text { de DH }\end{array}$ & $\begin{array}{l}\text { Sociedad } \\
\text { mexicana }\end{array}$ & $\begin{array}{l}\text { Estado } \\
\text { de } \\
\text { Derecho. }\end{array}$ & $\begin{array}{l}\text { Fundamentos Sociedad } \\
\text { de la } \\
\text { historia } \\
\text { sociopolítica }\end{array}$ & $\begin{array}{l}\text { Organizacion } \\
\text { (civil, } \\
\text { politica). }\end{array}$ & $\begin{array}{l}\text { Procuración } \\
\text { de justicia }\end{array}$ \\
\hline
\end{tabular}

El sujeto del MR es la sociedad, en los casos de análisis se representa por un agredido concreto y su dimensión institucional que se convierte en el sujeto del hacer en el MR. El "agredido" es un grupo social que entra en relación con el Estado quien, mediante sus cuerpos de seguridad o algunos de sus representantes, usurpa los derechos de algunos grupos; en el caso de Aguas Blancas se violentan los derechos de tránsito, manifestación y vida; hay una irrupción en el Estado de derecho, pero ésta no se verifica en realidad el día y hora de la matanza, sino que se va construyendo, y participan también los adyuvantes. Este sujeto del hacer es un sector de la sociedad que sintetiza las aspiraciones de otros grupos; los grupos pretenden la reivindicación del derecho a estar, a manifestarse, a existir. Representan la sociedad mexicana porque aspirar a encarnar (conscientes o no de ello) los valores sociales que fortalezcan una 
convivencia pacífica, no basada en un pacto por conveniencia (modus operandi) sino en reglas claras del juego político, aplicables a todos por igual sin distingos sociales, étnicos, políticos o culturales (mediación cognitiva).

El objeto no es una entidad fácilmente definible; en realidad "objeto" es una entelequia que agrupa un conjunto de aspiraciones, deseos que más que valores en abstracto son cuestiones concretas: seguridad, tranquilidad, derecho al trabajo en la zona y un largo etcétera que atraviesa por necesidades muy diversas, y que un mayor ejercicio de abstracción nos muestra derechos que pueden considerarse de segunda y tercera generación.

De cualquier forma, como lo explicamos en la caracterización más amplia del MR, la aspiración que revela las movilizaciones sociales (hoy caracterizadas a favor o relacionadas con derechos humanos) es la mejora de condiciones de existencia para una vida digna. Éste es el gran nivel lógico que se desprende o desagrega en otras formas o.modalidades específicas, como las demandas concretas de los grupos agredidos. La vida digna es más que una entelequia, es un programa que incluye la construcción de nuevas subjetividades y el desarrollo de la articulación comunicativa más amplia. La aspiración no se queda en las cuestiones materiales, se acompaña de lo que hemos llamado, con Habermas, la conquista del mundo de la vida y la consolidación del espacio público incluyente.

\section{Los ejes narrativos y los campos discursivos del relato de $\mathrm{DH}$}

En los conjuntos de noticias desprendidos de Aguas Blancas encontramos conjuntos de secuencias, hechos y declaraciones, en los que participan agresores directos (victimarios) y agredidos (víctimas), además de sus respectivos ayudantes.

Los ejes de este MR son tres, los cuales tienen su fundamento teórico en los ejes descritos por Greimas. En su aplicación al discurso periodístico de DH estos ejes son:

\section{Eje de la "agresión", el "querer" o la "búsqueda"}

Es el eje "disparador", lo que mueve a los sujetos a actuar. El sentido de la "generación" en el caso de los DH es muy variado. El "hecho generador" se encuentra en este eje; es "generador" porque convoca y dispara otros discursos.

Toda violación a los DH puede tener un rasgo generador porque es un discurso que "genera" un programa narrativo en la prensa informativa y, 
sobre todo, subordina otros textos a su marco para ser interpretados y evaluados; genera otros discursos y textos, otras visiones del entorno y una serie de acciones y declaraciones de actores involucrados que, mediante estos hechos, confieren nuevos sentidos a su propia acción y a las relaciones que sostienen con el Estado. "Genera" un nuevo orden, en tanto que ciertos acontecimientos construyen nuevas temporalidades y dan al espacio un nuevo valor.

Los actores de este eje primario (agredido-agresor) no usan el término "derechos humanos"; su visión es su propia corporeidad, su autorreflexividad se remite a la experiencia directa y usan el lenguaje que proviene de ella.

El "topos" del discurso de DH es la vida digna que implica una racionalidad de los actos humanos y la evaluación de todas las condiciones para el mayor desarrollo de la existencia humana. El discurso de los DH es un "discurso sobre la vida" porque su relato da cuenta de cómo los actores (victimarios, ayudantes, etc.) buscan mejores niveles de vida, reivindican demandas sociales, simbólicas. La búsqueda de una vida digna tiene una forma "pasional" relacionada con la dignidad de la persona, de los grupos sociales. Una violación de $\mathrm{DH}$ es un acto in-digno porque des-posee de la dignidad. La dignidad no es un valor que no se dé fuera de una implícita confrontación, conflicto o cuestionamiento.

\section{Eje del poder (de la participación o movilización)}

El eje del poder nos remite a acciones en el binomio adyuvancia-oposición. Para Greimas y Courtés (1990: 30, 292) el adyuvante designa al auxiliante positivo cuando ese rol es asumido por un actor distinto al sujeto del hacer: corresponde a un poder-hacer que en forma de actor aporta ayuda a la realización del programa narrativo del sujeto. En contraparte, el oponente es un auxiliante negativo, asumido por un actor diferente al sujeto del hacer; obstaculiza la realización del programa narrativo en cuestión.

Este es un eje institucional porque la movilización la realizan instancias sociales como son organizaciones sociales, partidos políticos, fracciones parlamentarias o bien sectores. La red institucional es un hecho fundamental, ya que, probablemente, sin ésta los hechos quedarían ocultos, o bien, sin la repercusión debida; en ese sentido éste es un eje "resonador". Una de sus manifestaciones en el MR informativo es el conjunto de declaraciones, manifestaciones y movilizaciones, en el que se re-define el sentido de los hechos, los grupos sociales que participan re-significan también sus propias relaciones y su vínculo con el Estado. Son, por otra parte, instrumentos en la traslación de los valores ("eje de la comunicación" en el modelo greimasiano) que se ponen en juego en el MR: "Estado de derecho", "pluralidad", "gobernabilidad", "justicia". 


\section{Eje del saber o de la comunicación}

El eje del saber o de la comunicación a nivel denotativo revela los participantes del proceso comunicativo (destinador-destinatario). El destinador comunica al destinatario-sujeto no sólo los elementos de la competencia modal, sino también el conjunto de los valores en juego; es también aquel a quien es comunicado el resultado de la performance del destinatario-sujeto que le corresponde sancionar.

Dentro de las aplicaciones que nos permite la definición de Propp-Greimas, caracterizamos el eje del saber como una especie de mediación cogniti$v a,{ }^{3}$ que permite la actualización del destinador-juez (como principio que regula las relaciones sociales, vía Constitución, reglamentos, leyes, procedimientos) mediante las acciones, interpretaciones y declaraciones de los actores agredidos y sus ayudantes, en primer lugar, aunque también en instancias que se ven confrontadas.

Este eje no se observará con claridad en las noticias que analizamos más adelante, pero existe como un componente necesario en el MR informativo que agrupa también el conjunto de noticias sobre los actores sociales -como el caso de las organizaciones civiles de $\mathrm{DH}$, que han sido in ${ }_{\mathrm{z}}$, urtantes en nuestra caracterización de aquellos actores participantes.

Otro de los fenómenos que reflejan la presencia de este eje es lo que llamamos el "discurso de la conmemoración". Al mes de los hechos, los actores "regresan" al lugar para reinterpretar el sentido de los mismos. Esta "conmemoración" (entendida como "volver a traer a la memoria") es el recordatorio (a una unidad de tiempo: un mes, un año, etc.) del hecho mismo; es obvio que la recordación no es anecdótica. Aquélla no tendría sentido sin su vinculación a la forma como los grupos apropian el sentido de la lucha. El discurso de la conmemoración es el centro en los vínculos entre el eje del poder y del saber, es una movilización (social, declarativa y epistémica) aunada a un saber que realizan los propios actores discursivos y también (en gran medida) el sujeto de la enunciación.

3. La mediación cognitiva se centra en la manera como determinados actores operan e intervienen en los hechos, a partir de un saber que han producido. Este saber tiene un origen en la investigación, en la referencia a fuentes. No es algo propio de un actor, aunque en nuestro trabajo queramos centrarnos en la mediación cognitiva que realizan las organizaciones civiles de derechos humanos; pero otros grupos, como la fiscalía mayor o algunos partidos políticos, poseen instancias productoras de un saber. Entendemos esta mediación cognitiva como el sistema de representaciones sobre sí mismos, sobre el otro y sobre el entorno de interacción; estos sistemas se ponen en funcionamiento para legitimar un orden, o bien para adyuvar al sujeto principal del hacer la realización del mismo; esta mediación opera a un nivel epistémico que se refiere a los mundos subjetivos que explican la interacción de los sujetos discursivos y de los cuales da cuenta el sujeto de la enunciación. 
Todo hecho violento inaugura una nueva temporalidad social: el mes, el medio año, el año se convierten en elementos nodales del MR para elaborar el sentido del hecho generador (y de alguna forma de las propias acciones). Este ritual confirma su importancia social y puede también redescubrir información. Este fenómeno de "construcción de temporalidades" lo realizan los medios de información, en cuanto hacedores simbólicos de los acontecimientos. Los medios extraen su información a partir de un concepto de la temporalidad, en el cual las fechas recubren otros significados aparte de su singularidad en el calendario de un año: aniversarios de personajes, batallas, publicaciones de obra; sumarios semanales, mensuales, anuales, son hilos de un tejido de rituales que forman parte de la agenda de los medios de información. Esta es la conmemoración de los medios que tiene muchas estrategias en las rutinas de los sistemas informativos.

\section{Los campos socio-discursivos del MR informativo de $\mathrm{DH}$}

Junto con los ejes narrativos, también nos ayuda a caracterizar el MR informativo de DH los "campos socio discursivos" (CSD) que definimos como espacios de producción discursiva en su dimensión espacial y simbólica. Estos CSD son instancias enunciativas, lugares institucionales y simbólicos desde los cuales los discursos se producen y el mediador de la prensa los incorpora en la construcción del relato de prensa. Los CSD pueden identificarse como sub-relatos o micro-secuencias dentro del MR y nos ayudan teóricamente a organizar el juego polifónico donde se anudan todas las voces-enunciadores que participan en el MR.

Los CSD pueden ser en su dimensión "inmediata", "nacional" (estructural) o "internacional" (metaestructural). En el campo inmediato estudiamos el "discurso del sobreviviente", por una parte, y el "discurso del agresor (inmediato)" y del "agresor mediato" (como autoridad, instancia de gobierno). En el estudio de la prensa veremos las estrategias que la prensa utiliza y los niveles de distancia enunciativa que establece con uno y otro polo de este CSD.

El segundo CSD es el mediato (o estructural) en el que ubicamos el "discurso de la autoridad" en su dimensión institucional (Ejecutivo Federal, Ejecutivo Estatal; Secretaría de Gobierno, órganos de procuración de justicia), de los partidos políticos, de la mediación (legislativo, social), de las organizaciones sociales y de las organizaciones civiles de $\mathrm{DH}$. El estudio de este segundo CSD nos permite dar cuenta de todas las interacciones entre las fuentes enunciadoras que el mediador selecciona para construir el escenario 
de voces. Como en el primer CSD el locutor mediador deja ver estrategias en su relación con estas voces. ${ }^{4}$

Finalmente, el CSD metaestructural en el que estudiamos "el discurso internacional"; es decir la inserción de enunciadores internacionales en el MR informativo, tales como organizaciones, grupos o gobiernos internacionales, organizaciones internacionales de DH, de las cortes supranacionales, de los gobiernos extranjeros (principalmente norteamericanos y europeos) y de los grupos civiles y de solidaridad (principalmente norteamericanos y europeos).

Estos dos conceptos (ejes narrativos y CSD) nos ayudan a intervenir el vasto campo de noticias que un hecho violatorio de DH puede convocar; nos facilitan la identificación de nudos de condensación del sentido para centrar la mirada cualitativa y discursiva en esos puntos y conocer no sólo la constitución del relato de prensa, sino sobre todo el proceso discursivo ejecutado por el sujeto de la enunciación (en nuestro caso, el locutor-mediador en tres medios de referencia dominante).

\section{Anotaciones metodológicas}

Algunas de las contribuciones que, consideramos, aporta nuestro trabajos son: a) caracterización teórica del MR informativo de prensa sobre un hecho violento; b) propuesta epistemológica para un acercamiento diacrónico en la construcción del acontecer pública; c) las aportaciones que puede hacér la semiótica al estudio del discurso público de los $\mathrm{DH}$; y, finalmente, d) la promoción del estudio del discurso sobre los $\mathrm{DH}$ y en particular sobre el discurso de prensa.

En nuestro marco teórico hemos acudido en un principio al modelo greimasiano para seleccionar, dentro de todo el campo informativo que despliega un hecho noticioso violatorio de los $\mathrm{DH}$, algunos conjuntos de noticias; de todas ellas, las más importantes son las que hemos llamado "noticias generadoras". También caracterizamos la dimensión narrativa de la noticia (lo mismo en su mismidad sincrónica que en el acercamiento diacrónico que proponemos).

Junto con esta variación de la semiótica greimasiana nos han sido de mucha utilidad algunos principios de la lingüística textual de Van Dijk y sus aplicaciones al discurso periodístico. En particular, este último ha sido uno de los autores que ha hecho un esfuerzo por aplicar sus categorías al discurso de prensa.

4. Por ejemplo, el hecho que observamos en el caso Aguas Blancas, la poca presencia de organizaciones sociales en el MR del periódico Reforma. 


\section{Las macroestructuras del discurso de la prensa informativa}

Teun Van Dijk (1990) es un autor muy conocido en el ámbito del análisis del discurso, pero también del estudio discursivo de la prensa. El libro que hemos citado no es el único. Con una extensa trayectoria de varias décadas, ha partido de la semántica formal para construir modelos de análisis aplicables al estudio de los mensajes massmediáticos, como muestra el gran proyecto que desde hace algunos años emprende en sus estudios sobre el racismo. En sus trabajos, Van Dijk acude originalmente a la filosofía y, sobre todo, a la lógica para proponer modelos que expliquen el sentido y la referencia de las expresiones.

En términos generales, la idea de análisis del discurso en Van Dijk (1978: 55) proporciona una aproximación analítica que parte del conjunto del texto (unidad global), en lugar de partir de la oración y sus componentes. El texto posee una estructura que debe respetar las condiciones de coherencia global. El investigador puede conocer esta coherencia mediante el estudio de la representación abstracta de la estructura global y local de significado de un texto. La hipótesis central del autor es que el discurso se forma de unidades superiores de contenido llamadas macroestructuras (ME), que son proposiciones subyacentes que representan el tema o "tópico" de un texto (macroestructura semántica), y constituyen un elemento importante de cohesión del texto.

Una de las formas para aprehender el sentido global del texto consiste en identificar los temas o tópicos traducibles en una serie esencial de macroproposiciones; para poderlas derivar el autor sugiere el procedimiento metodológico de las macrorreglas (Van Dijk, 1978: 58), las cuales permiten organizar la información de las proposiciones o la representación abstracta de lo que llamamos información (semántica).

Van Dijk $(1990,1997)$, a diferencia de otros autores que se han dedicado al análisis del discurso desde distintas perspectivas, nos ofrece un intento metodológico de aterrizar las premisas básicas de su obra en la construcción de un modelo de análisis del discurso periodístico. En el discurso periodístico podemos identificar con relativa facilidad estructuras esquemáticas convencionales. Una estructura esquemática consiste en una serie de categorías jerárquicamente ordenadas, muy similares a las categorías de un esquema narrativo (planteamiento, compilación, resolución, évaluación y moraleja). De manera paradigmática, las noticias periodísticas exhiben información en tres tiempos: titular, entrada y cuerpo. Las tres proporcionan una muestra clara de lo que se entiende por tópico del texto o tema. En varias de sus obras, Van Dijk ha estudiado el esquema que da forma a la realización de la noticia: 
se trata de superestructuras, es decir, la forma en que una macroproposición (tema) se organiza como esquema.

Las noticias tienen una estructura más o menos convencional que facilita al usuario/lector la identificación, así como reconocer las distintas partes del texto. Una estructura esquemática consiste en una serie de categorías jerárquicamente ordenadas, muy similares a las categorías de un esquema narrativo (planteamiento, compilación, resolución, evaluación, moraleja) (Van Dijk, 1978: 153-157) y que traducidas al discurso periodístico puede ser: resumen (titulares, entrada), relato periodístico que tiene episodios y comentarios, los cuales se subdividen en sucesos previos, actuales, expectativas, evaluación de los hechos, hasta llegar a categorías como antecedentes generales y contexto actual. Van Dijk utiliza esta pirámide, o árbol, en varias de sus obras para explicar la macroestructura de un texto como la noticia.

\section{La idea de argumentación en el discurso informativo}

La idea de argumentación o persuasión figura, en apariencia, como contraria a los objetivos que tiene toda noticia (o texto informativo, como puede ser una entrevista y una crónica). Con Bateson (citado por Calsamiglia y Tusón, 1999: 294) la vemos como un hacer creer o un hacer hacer -o ambas cosas- a un interlocutor o a un público.

Dentro de los múltiples enfoques que se han producido desde muy distintas áreas el más funcional y, al mismo tiempo, complementario en nuestro marco metodológico es el enfoque semántico-argumental de Anscombre y Ducrot (1994), el cual concibe al texto en sus objetivos de hacer-creer como el principal programa pragmático y mediante una serie de conectadores. La hipótesis de la argumentación en la lengua defiende que la argumentación está inscrita en la lengua; Anscombre y Ducrot se preocupan por ver los principios que determinan la adecuación de los enunciados con respecto al contexto lingüístico en que aparecen (es decir, lo que es o no adecuado como continuación de una determinada frase). Se trata de estudiar cómo y por qué se realizan los encadenamientos en relación con su dirección ilocutiva concreta.

La argumentación se entiende como aducir razones en favor de una determinada conclusión (Escandell, 1993: 92). La teoría en su conjunto desea mostrar cuáles son los elementos, las reglas y los principios que determinan la organización externa y la interpretación de las argumentaciones. Es decir, buscan una semántica ampliada que abarque también a la pragmática, por eso su enfoque es conocido como "semántica argumental" en la que no sólo la conclusión puede determinar semánticamente el argumento, sino que el argu- 
mento también determina semánticamente la conclusión (Anscombre y Ducrot, 1994: 20).

El texto (o conjunto de ellos) lleva una intriga en la que se dan relaciones causales entre los acontecimientos (distintos niveles). En el carácter sintético de la noticia, éstos se articulan mediante conectores ("por otra parte", "a su vez", "mientras tanto", etc.) en el que el relato es sujeto de un determinado encadenamiento y lleva a una conclusión que en principio concluye con la instrucción del titular. El carácter persuasivo se da en la lógica (jerarquización y articulación) de los encadenamientos que permiten al lector inferir (presentir) si la información del texto fue suficiente para cubrir la pregunta implícita en los enunciados del encabezamiento.

\section{Acercamiento al proceso de producción discursiva de la prensa informativa desde la retórica}

Junto a las consideraciones socio-semióticas que permiten estudiar al texto periodístico como un proceso de producción (Rodrigo Alsina, 1989), podemos completar nuestro acercamiento teórico (Greimas, Van Dijk, Ducrot) con una caracterización amplia desde la retórica para precisar las etapas que intervienen en la confección del texto.

Cervini (2000) y Sosa (2000) han hecho una interesante aproximación a la noticia desde el proceso retórico. La retórica interviene cuando se necesita convencer a alguien de algo; la noticia, para ser ( $\mathrm{y}$ hacerse) creíble, debe convencer de que el contenido de la información es verdadero. El proceso de producción informativa puede explicarse desde las etapas tradicionales de la retórica (inventio, dispositio y elocutio) y conocer el recorrido que el sujeto de le enunciación sigue en la confección de insumos cooperativos y pragmáticos acerca de un suceso; la disposición y jerarquización de dichos insumos y la elección de estrategias y recursos en su formulación lingüística.

\section{La inventio}

La inventio (del verbo latino invenire, "encontrar") es la primera parte de la retórica, que corresponde a la primera fase de preparación de todo discurso oratorio: la concepción de sus contenidos, que abarca la selección de los argumentos y las ideas sobre las que después habrá de implantarse un orden considerado por la dispositio. En término generales, podemos decir que la materia de la inventio es lo que hoy llamamos contenido; en esta fase, se procuran orientaciones acerca de cómo buscar las ideas generales que se han 
de esgrimir como argumento y que, una vez halladas, en la siguiente fase se han de ordenar (Beristáin, 2000: 274). La inventio abarca todo lo relativo a la concepción del discurso, al hallazgo de las ideas generales, los argumentos, los recursos persuasivos; examina cada una de las otras operaciones posteriores (dispositio, elocutio, actio) desde el punto de vista del emisor, receptor y mensaje.

\section{La dispositio}

La dispositio organiza armónicamente, distribuyendo dentro del todo del discurso sus grandes partes fijas instituidas. La dispositio corresponde al desarrollo de la estructura sintagmáticamente del discurso, el orden elegido debe resultar favorable a los fines del mismo. Beristáin (2000: 158-159) señala que las partes de la elocutio son exordio o proemio, narración o acción, confirmación, argumentación o prueba y, finalmente, epílogo. Si la inventio es búsqueda, la dispositio trata de dar orden, dentro de los apartados, a esas ideas y esos recursos. Las noticias tienen una estructura global que les permite ser identificadas como correspondientes a una misma clase (Cervini, 2000: 4). Aun coexistiendo con otros tipos de textos en el mismo medio -el editorial, las columnas, los comentarios, los avisos clasificados, los anuncios publicitarios- las noticias se identifican como tales. Este reconocimiento es posible porque poseen una "forma de presentación", así como una "superestructura": estructura formal convencionalizada común a todos los textos-ocurrencia que adscriben a la misma clase textual.

\section{Elocutio}

Los antiguos consideraban a elocución como el "ropaje lingüístico" con el que se visten las ideas; para algunos es también sinónimo de estilo. Dentro de la elocutio se procede a la elección (electio) de los tropos y figuras, y además se realiza la composición (compositio), que consiste en disponer las expresiones, conforme al orden sintáctico, dentro de cada oración y cada frase.

La noticia es un género que ha logrado un máximo de estabilización $-\mathrm{y}$, por lo tanto, de previsibilidad-- en el conjunto de sus rasgos elocutivos más significativos, los que se vinculan con el predominio de la función referencia o representativa; sin embargo, no llega a constituir un texto de "grado cero", porque no siempre los procedimientos de evidencialidad contienen indicadores de alto grado de certeza - como ocurre en la información científica. Uno de los principales recursos de la noticia son los mecanismos de evidencialidad, por medio de una selección de modos verbales, adverbiales y construcciones, que pretende funcionar como instrumentos de precisión en la información. 
Estos mecanismos constituyen uno de los principales recursos para comprobar la instrucción del titular en el cuerpo de la noticia y, sobre todo, en el principio de verosimilitud (credibilidad) de la propia noticia, que para un mediador es fundamental en su relación pragmática.

Toda vez que hemos hecho esta caracterización, estamos en la posibilidad de presentar el análisis de las noticias generadoras en el caso Aguas Blancas.

\section{Anotaciones sobre la noticia generadora (NG) del caso Aguas Blancas (AB)}

El sexenio de Zedillo fue muy paradójico en materia de DH: se dieron importantes avances (las visitas realizadas por funcionares internacionales, la aceptación de la judicatura de la Comisión Interamericana de DH); sin embargo, los índices de violaciones a los DH aumentaron. Dentro del repertorio de hechos violatorios, sin duda los casos de Aguas Blancas y Acteal fueron los más significativos.

En su conjunto, en el sexenio zedillista no se avanzó significativamente en la mejora del estado de las garantías individuales, sociales y culturales en el país. Zedillo no fue el presidente más autoritario y despótico dentro del nacionalismo revolucionario, su sexenio, en cambio, fue uno de los más violentos a causa de un gran inestabilidad institucional y el desmantelamiento de las instituciones de procuración de justicia.

El listado de eventos violatorios impresiona por su diversidad: su mandato, el 1 de diciembre de 1994 se inaugura con agresiones a periodistas, siguen los eventos en Chicomosuelo (Chiapas), detenciones de presuntos miembros zapatistas, allanamiento de la policía judicial, el conflicto de Ruta 100, el asesinato de Polo Uscanga, el caso AB y una serie de matanzas en el estado, el caso Tepoztlán y un larguísimo etcétera que tuvo su punto más alto en los hechos de Acteal (diciembre de 1997).

Este periodo ofrece características idóneas para observar a los DH en esa lucha entre la disolución del sistema político mexicano y la creación de nuevas reglas dentro del mismo, sumado a una correlación internacional de hechos que colocan al gobierno en el punto central de los compromisos comerciales a nivel internacional y las presiones internas por un Estado de derecho. Estas transformaciones se presentan también en la prensa, en primer lugar por el papel de los DH en el discurso informativo, la creación de nuevas fuentes y una relación de los medios con los productores de la noticia de DH (v. gr. organizaciones civiles de DH).

El 28 de junio de 1995, policías estatales asesinaron a 17 campesinos de la Organización Campesina de la Sierra del Sur (OCss), en el vado de Aguas 
Blancas, municipio de Coyuca de Benítez, Guerrero. El fiscal asignado para realizar las investigaciones, Óscar Varela, exculpó al gobernador Rubén Figueroa y a sus colaboradores, y el Presidente solicitó a la Suprema Corte de Justicia de la Nación que reabriera el caso. Mientras se realizaban las pesquisas, un video mostró que los campesinos no empezaron la agresión. El 11 de marzo de 1996 Figueroa Alcocer solicitó al Congreso local "licencia definitiva" para separarse de su cargo y "facilitar la investigación". El 23 de abril, la SCJN concluyó que se manipularon pruebas, se alteró la escena del crimen y los policías sembraron armas a los campesinos. Determinó que el gobernador y sus colaboradores incurrieron en conductas que podían tipificarse como delitos penales. Los diputados federales del PRI se negaron a iniciar un juicio de procedencia contra Figueroa e impidieron que se le enjuiciara penalmente. En el primer aniversario de la matanza apareció el grupo armado denominado Ejército Popular Revolucionario (EPR).

Fueron consignados por los delitos de homicidio, lesiones y abuso de autoridad Esteban Mendoza, ex delegado de Gobernación; Rodolfo Sotomayor Espino, ex subprocurador de Justicia; Manuel Moreno González, director operativo de Tránsito, y agentes de la Policía Motorizada. ${ }^{5}$

\section{Titulares y encabezamientos}

Para Van Dijk (citado por Peñamarin, 1997: 150) la lectura de los titulares es un proceso de adivinación estratégica, por el cual el texto accede a una situación críptica de los sucesos o temas de la noticias, recupera información previamente conocida, incorpora suposiciones y conjeturas, comprueba su conocimiento del asunto episódico y la adecuación con las tipificaciones existentes en la memoria semántica del lector. Con ello, el lector decide si leerá o no el cuerpo de las noticias. Estas formas esquemáticas totalizadoras se llenan con los significados macroestructurales totales o temas de un discurso. En el siguiente cuadro colocamos el encabezamiento de las tres noticias generadoras (cfr. J29/6-1,18a, U29/6-17, R20/6-1A). ${ }^{6}$

5. Cfr. "Saldos del sexenio", en La Jornada, 2 de septiembre de 2000, p. 13.

6. Colocamos la referencia a las noticias con este proceso de citación que no corresponde con el proceso citacional que en términos generales hemos seguido (el sistema anglosajón; también conocido, APA). La referencia incluye la primera letra del diario. En el caso de los tres diarios, los colocaremos en este orden: J, U y R, el día y el mes (el año es 1995), la página y su ubicación. 


\begin{tabular}{|c|c|c|}
\hline La Jornada & El Universal & Reforma \\
\hline $\begin{array}{l}\text { (T) } 16 \text { Campesinos asesinados en Guerrero. } \\
\text { (AT) Emboscada de la policia: sobrevivientes; } \\
\text { repelimos agresión: autoridades. }\end{array}$ & $\begin{array}{l}\text { (T) Enfrentamiento de } \\
\text { campesinos y policias } \\
\text { en Coyuca de Benítez; } \\
18 \text { muertos }\end{array}$ & $\begin{array}{l}\text { (T) Mueren } 14 \text { en } \\
\text { enfrentamiento }\end{array}$ \\
\hline
\end{tabular}

El primer dato que llama nuestra atención es la caracterización del hecho violento. ${ }^{7}$ De acuerdo con la información de los titulares en La Jornada (J), vemos principalmente la calificación del hecho como "asesinato" lo que de suyo es una guía, la cual nos permitirá seguir el relato a partir de esta hipótesis ("asesinato", "acción premeditada del agresor") ${ }^{8} \mathrm{El}$ "asesinato" connota una visión pasiva del sujeto (los campesinos de la OCSS). El encabezamiento se presenta en forma de versiones encontradas y de una mayor especificación en dos subcategorías por parte del agredido: "unos iban a vender", "otros iban a un mitin". Existe una cualificación simbólica diferenciada: actor-campesino, actor-campesino politizado; ésta será una de las principales estrategias de $\mathrm{J}$ en la caracterización del agredido: la politización del agredido y su vinculación orgánica a una estructura.

En El Universal (U), agredido-agresor, los actores se "enfrentan", es decir se parte de una caracterización activa del agredido. Los actores enunciados aparecen enmarcando la acción en un espacio más definido "Coyuca de Benítez" (municipio de la sierra de Atoyac, en Guerrero), ${ }^{9}$ a diferencia del criterio de espacialización más amplio en $J$ (el nombre de la provincia).

En Reforma (R), su titular es muy breve; como tal, cumple la función meta-textual de anunciar el tipo de texto que el lector encontrará: un resumen comprimido, con algunos hechos e información acotada. La brevedad introduce un elemento persuasivo, propio de la titulación en prensa que despierta ciertas preguntas (¿quiénes se enfrentaron?, ¿por qué?). La expectativa de la pregunta se refuerza en el titular por la ausencia de deícticos espacio-temporales.

7. Entendemos por caracterización una estrategia discursiva que puede presentar personajes, objetos, lugares, épocas, procesos o hechos. No es un tropo, es una figura de pensamiento o "figura de estilo" (Beristáin, 2000: 136), donde se refiere a la descripción pero cuya definición puede aplicarse a lo queremos decir por caracterizar.

8. Hablar de "asesinato" o "enfrentamiento" implica estructuras relacionales distintas agredido-agresor; en el primer caso, se presupone un victimario, una víctima y ciertas circunstancias que el lector mexicano puede presuponer por leer "Guerrero" o "Figueroa". El "asesinato" incluye "rasgos semánticos" como premeditación, alevosía y ventaja; es decir, estados intencionales del sujeto que pueden presumir estados pasionales como odio o animadversión.

9. Es decir, Coyuca no es un lugar de paso, sino un sitio establecido, ubicado en el mapa y en una zona preestablecida como lugar de confrontaciones en el pasado mediato por la guerrilla de Lucio Cabañas, quien combatió y murió en esa zona. 


\section{La espacio-temporalidad de las NG}

Los hechos violentos poseen un cronotopo..$^{10}$ En los casos que analizamos vemos que los espacios tienen una fenomenología: la circunscripción a la sierra, el lugar accidentado y escondido, el "lugar de paso" o bien un "lugar en el mapa"; J, por ejemplo, aunque en el párrafo (párrafo 2) lo enmarca dentro en la "Sierra de Coyuca", ésta es una indicación toponímica de un sitio ubicado en el mapa con indicadores que permiten precisar su localización. El mediador en $U$ alude a Aguas Blancas como comunidad, pero al párrafo siguiente uno de los actores se refiere al hecho del "lugar de paso". En resumen, podemos decir que la caracterización topográfica va de la movilidad ("lugar de paso") a la inmovilidad ("lugar establecido").

Una de las estrategias de temporalización en las NG consiste en la ubicación de los sujetos enunciadores, los cuales pueden colocarse en distintos tramos de una secuencia temporal. Por ejemplo, la noticia en $R$ señala dos sujetos enunciadores básicos (el dirigente municipal del PRD y la información oficial de la Policía Judicial), de los cuales el lector obtiene la información; éstos no se encuentra en planos temporales diferenciados, en tanto más que un relato el texto en $R$ presenta informaciones contrastadas. $U$ ubica las acciones del relato en distintos planos temporales, implica un nivel de complejidad en tanto ubica desplazamiento temporales en el relato: acciones del PRD en presente, mientras que las declaraciones son en pasado. ${ }^{11}$

El lector de J tiene la mayor información, pero al mismo tiempo tiene que realizar el mayor esfuerzo cognitivo para organizar el complejo escenario de actores que puede convocar el locutor-mediador en los párrafos 28 y $29^{12}$ en

10. El término proviene de Bajtin. En 1925 Bajtin escuchó a Ujtomski, científico soviético, la descripción del concepto de cronotopo que éste acuñó basándose en la biología y la teoría de la relatividad, término que más tarde él mismo habría de reformular y adaptar al campo de la cultura y el análisis literario, como una categoría de forma y contenido; la noción tiempo-espacio. En otras palabras, la intervinculación esencial de las relaciones temporales y espaciales, asimiladas artísticamente en la literatura merced a la indivisibilidad del espacio y del tiempo. En el terreno de la creación verbal, la cronotopía debe tener correspondencia en los elementos estructurales del texto, pero ha de ser, esencialmente, una caracterización de la visión del mundo (cfr. Beristáin, 2000: 117).

11. "Militantes del Partido de la Revolución Democrática (PRD), que realizan un "plantón" frente al palacio municipal de esta población, manifestaron su rechazo a la "política de sangre" que impera en la entidad y demandaron el esclarecimiento inmediato de los hechos, ya que sus compañeros no se dirigían a apoyarlos".

12. (28) "El palacio municipal de Coyuca parecía abandonado. El alcalde Jesús Herrero Vélez, se encontraba reunido con el secretario General de gobjerno, Rubén Robles Catalán, el director general de seguridad pública del estado, Rosendo Armijo de los Santos, y el director de la Policía Judicial Gustavo Olea Godoy, en una bodega particular, donde se negaron a recibir a los reporteros". (29) "Cerca de esa bodega se había instalado un cuartel provisional de la Policía del estado, comandada por Manuel Moreno, donde se encontraban concentrados cientos de agentes fuertemente armados, la mayoría integran- 
el estilo discursivo Oratio Quasi Oblicua (OQO), ${ }^{13}$ lo cual da una mayor libertad en la construcción del relato y diluye las fronteras entre el sujeto de la enunciación (SE) y el sujeto enunciador. Esta será una constante que se observará en todo el MR.

\section{Las variantes en la estructura citacional}

Otros de los aspectos que observamos a nivel de discurso en las NG es la forma como el SE construye el texto mediante la combinación de citas y los intercambios que realiza entre los sujetos discursivos (enunciadores enunciados) y su rol dentro de la noticia. Los teóricos de la intertextualidad señalan que uno de los procedimientos para estudiar los procesos de apertura en el texto es mediante la citación.

La estructura citacional es el conjunto de reglas que operan sobre los modos de transmisión de palabras ajenas. En las noticias, el SE retransmite otros discursos mediante estilos que revelan estructuras dialógicas entre el locutor-mediador y la fuente enunciadora. La estructura citacional es uno de los principales mecanismos para conocer la construcción del discurso (Reyes, 1984: 206-208) e indagar por la representación del propio SE.

Al observar las noticias, vemos que en $J$ existe una mayor tendencia a marcar el discurso por los procedimientos más diversos (léxico-frástrico y de periodo), esto revela un locutor-mediador más activo que se marca con mayor constancia sobre la superficie textual. En J, tenemos también un tratamiento estilístico más diferenciado: no priva únicamente el Estilo Directo (ED) o Estilo Indirecto (EI), observamos combinaciones con Estilo Indirecto Libre (EIL) y Oratio Quasi Oblicua.

En cuanto a U, observamos citación léxica (“plantón”, párrafos 8,22 ; “política de sangre", párrafo 8; "emboscada”, párrafo 11) en su doble función de marcador oral de un término o en su pluralidad semántica (referencia a otro sentido connotativo). Una de las variantes citacionales más interesantes es la "citación en cascada" (alguien cita a un primero, que a su vez cita a un

tes de los grupos que realizaron la emboscada cerca de Aguas Blancas".

13. Muy cercana al Estilo Indirecto Libre se encuentra la Oratio Quasi Obliqua (OQO), de uso muy frecuente en la prensa informativa que Reyes (1984: 208-209) contextualiza dentro de un modelo de transmisión periodística que describe del siguiente modo: -El diario dice que la fuente dice que un sujeto hizo (dijo que) $X$; o, si no se trata de acciones sino de acontecimientos sin agente humano: $-E l$ diario dice que la fuente dice que $X$. Lo cual se subsume en: $-S$ (el narrador de la noticia) dice que $S$ - $F$ (su fuente) dice que $S$ hizo (dijo que) $X$. La OQO es una paráfrasis libre e informada por la perspectiva del hablante (citador) y que no presenta marcas sintácticas explícitas de citación, que se percibe como una forma de cita en virtud de la información contextual. 
segundo, etcétera). Este acto de lenguaje (afirmación de otra afirmación) revela un procedimiento para recolectar la información, pero también confiere valor a los niveles de enunciado: la fuente original (chofer del camión) es un actor que en principio no habla por sí mismo, se le conoce por un segundo (el funcionario).

El caso más complejo de citación lo tenemos en los párrafos 5 y 6 de $\mathrm{J} ;{ }^{14}$ el sexto párrafo abre un conector argumentativo ${ }^{15}$ que contrapone dos perspectivas o conclusiones posibles. A su vez, este SE introduce otro enunciador que es la regidora por el PRD (aquí tenemos otro acto de habla - AH- o acto de enunciación) que informa sobre otra persona (el párroco de Coyuca), quien a su vez realiza una serie de acciones. En este proceso citacional, observamos las tres instancias enunciativas que encuentran presentes en todo el relato: fáctica, enunciativa y cognitiva. El párroco "logró llegar" (fáctico), "observó" (cognitivo) y "declaró" (enunciativo). En la propia estructura de la cita, aparece la referencia a esas tres dimensiones. La única cita directa de este segmento es la que se atribuye al párroco ("[...] los oyó decir"). Sólo en este punto el contenido enunciativo puede ser íntegramente atribuido, en su entero significado y sentido axiológico, al enunciador citado (el párroco).

En $\mathrm{R}$ tenemos, por el contrario, un estilo citacional mucho menos complejo; el locutor-mediador presenta estructuras canónicas en el discurso informativo (v. gr. porciones citadas con verbo asertivo al final). ${ }^{16}$ Sólo en el sexto

14. (5) "Durante 4 horas, el contingente de la Policía del Estado a cargo de Manuel Moreno, estableció un cerco alrededor del lugar de la matanza e impidió el paso a toda persona". (6) "Sin embargo, la regidora por el PRD Ernestina Rojas Justo, informó que el párroco de Coyuca, Hugo Hernández Maldonado, logró llegar hasta el lugar de los hechos y observó que los policías colocaban armas largas en manos de algunos de los muertos, ‘y los oyó decir que los querían acusar de que eran guerrilleros zapatistas o narcotraficantes"”.

15. "Sin embargo" es uno de los conectores que más ha sido estudiado. Es un conector del discurso polémico. En este caso la argumentación parece que llevará a otra conclusión. Para Caballero y Larrauri (citados por Calsamiglia y Puson, 1999: 299) es un conector de oposición que señala que los enunciados que vienen a continuación contienen alguna diferencia respecto de los que le preceden. La diferencia puede no ser más que un matiz $o$, por el contrario, puede ser algo totalmente opuesto a lo afirmado anteriormente; y esto se utiliza justamente para dar una mayor fuerza o peso a este segundo argumento.

16. Como ejemplo transcribimos la segunda parte de la noticia (cfr. R29/6-1A) (4) "Unos 60 compañeros viajaban cerca de las 11:00 hrs. en una camioneta, luego de abandonar Tepetixtla, cuando se encontraron a un grupo de 80 policías que estaba apostado en el camino y les empezó a disparar', afirmó". (5) "Las primeras 10 personas murieron de manera instantánea, agregó, y 5 más unos momentos más tarde". (6) "El grupo conforma la Organización Campesina de la Sierre del Sur e iba a Atoyac de Álvarez para exigir la entrega de uno de sus compañeros desaparecidos desde el 24 de mayo pasado". (7) "La Procuraduría estatal informó que en lugar de los hechos fueron encontraron un rifle AK-47 o 'cuerno de chivo', abastecido con 20 tiros; una escopeta Thompson calibre.12; una pistola Colt calibre. 38 súper; otra .45 ; una calibre .9 milímetros, y una .25 , así como un rifle calibre .22". (8) "Asimismo se recogieron 6 cascajos calibre .45 , cuatro cascajos de una AK-47, 12 cascajos .9 milímetros y dos más .38 súper', señaló en el comunicado". 
párrafo el SE asume el papel protagonista de narrador para darnos antecedentes. En los últimos dos párrafos $(7$ y 8$)$ se vuelve a alternar EI y ED. Las estructuras son más o menos regulares y estándares; el SE afirma su rol de organizador en la información pero no se permite muchas licencias, y dentro de lo limitado de su espacio toma de manera protagónica la palabra —en el párrafo 6- para darnos información del grupo reprimido, al cual define y enmarca simbólicamente.

\section{El relato del sobreviviente (RS) en las NG}

Uno de los insumos pragmáticos más importantes es la referencia al RS como una forma de conocer de "primera mano" lo que sucedió. El RS es la narración de un actor discursivo privilegiado porque constituye la fuente más cercana a lo que sucedió. El RS es uno de los principales recursos informativo con los que cuenta el locutor-mediador para legitimar su acción informativa y conferir el valor hacer-creer a la noticia.

El principal acto de lenguaje del RS es la evocación y el recuerdo. Su primer componente es el valor emotivo del relato como tal (la historia que cuenta), que lejos de ser una secuencia lineal es un retablo a la manera de fragmentos. El segundo valor es que es un relato no causal: no se prescinde de explicaciones, pero el principal componente se centra en la dimensión de la experiencia del "yo-narrador". Podemos señalar algunos otros rasgos genéricos de este RS: está impregnado de una visualización del entorno, donde el sobreviviente ubica el agresor, el lugar donde se encontraba y lo que alcanza a ver desde el "punto de visión" (el escondite: debajo del asiento, debajo del autobús).

En J, el primer informante personalizado es Apolonio Romero, provisto esta vez de doble-institucionalidad (miembro de la ocss, simpatizante del PRD). Apolonio también es presentando en el discurso mediante las huellas que pueden ser corporales ("sólo recibió un rozón de bala en un dedo") y también sociales ("pasajero proveniente de Atoyaquillo que viajaba acompañado de su hijo [...] quien murió en la emboscada").

El sobreviviente aparece en $J$, como lo señalamos desde el encabezamiento, en su diferenciación productiva ("eran campesinos, iban a comprar maíz") y política ("iban a un mitin"). Apolonio Romero, el principal enunciador-informante, es sometido a varios procedimientos discursivos (ED, EI, OQO). De su relato destaca que no se asume como miembro del PRD, hace una calificación del hecho. El centro de su relato está en el párrafo $18,{ }^{17}$ en el que se

17. "Dice que sólo esta camioneta fue agredida. 'Nosotros no disparamos, no traíamos armas. Empezamos a recibir la agresión desde lejos, del monte. Al sentir los disparos nos 
muestra la asimetría agresor-agredido y sobre todo se refuerza la tesis de la emboscada, sostenida conjuntamente por el sujeto de la enunciación. La marca del "nosotros" y el "ellos" facilita al SE la organización del "ellos" (agresores), versus el "nosotros" (agredidos). Apolonio, como sujeto-informante, es sometido a un proceso de caracterización para ofrecerle a su intervención los elementos de verosimilitud como informante legítimo y válido (el "rozón del dedo") y alteraciones sintácticas que el SE concede en la citación, como ciertas repeticiones caracterîsticas del discurso hablado ("No nos marcaron el alto, nomás nos empezaron a tirar y a tirar y a tirar").

Los sobrevivientes citados en $\mathrm{J}$ no asumen ningún tipo de consigna a favor de una lucha. Sin embargo, en el relato hay una separación del "nosotros" ("miembros de la ocss") "ellos" ("infiltrados en los autobuses, que nadie los conocía"). Así, aunque no haya consignas, el sobreviviente asume la agresión en su vinculación política e institucional y asociada a un programa de actividades ("iba a pedir fertilizantes, a demandar la presencia de compañeros desaparecidos desde el 24 de mayo"). Estas dos demandas se encuentran en órdenes distintos: el Estado en su obligación asistencial y como represor político.

Aunque el principal acto de habla es la evocación como tal, podemos encontrar otros actos asertivos y cognitivos del RS ("dicen", "explican", "narran", "exponen", "recuerdan", "aseguran"). En los enunciadores citados por J vemos algunas diferencias: Apolonio es más autoexplícito en el acto de agresión ("nos acribillaron [...] al terminar la masacre"). Dionisio se centra más en lo denotativo del testimonio, y el discurso de la memoria y la evocación como operación fundamental. ${ }^{18}$

alarmamos, no sabíamos qué hacer viendo que estaban cayendo compañeros. Gritábamos que nos dispararan, que éramos pasajeros. No les importó: siguieron disparando y disparando, incluso a las personas que estaban moribundas les daban el tiro de gracia, los remataban. De nosotros no hubo ningún disparo".

18. En otras unidades de análisis (como una entrevista que realiza $\mathrm{J}$ a miembros de la OCSS, y que aparece en la prensa el 1 de julio de 1995), el SE caracteriza a los sobrevivientes de manera más racional y argumental, realizan procesos lógicos y llegan a inferencias por ellos mismos, se presenta un sobreviviente más autorreflexivo; el recordar se convierte en conocimiento de lo que pasó y por qué sucedió, como por ejemplo en la siguiente cita de esta entrevista (J1/7-8; párrafos 8-10): (8) "Eran blancos y vestían como cualquier de nosotros. Pensé que eran miembros de la organización cuando se cambiaron de camioneta, pero nadie los conocía. Luego pensé que eran de algún pueblo y viajaban para vender o comprar algo en Coyuca, pero no traían cosas. Nadie los conoció". (9) "La gente los vio dice que venían armados, y que cuando llegamos al vado de Aguas Blancas fueron los primeros que se bajaron cuando los policías nos gritaron que nos paráramos". (10) "Algunos compañeros vieron que estos hombres que traían fierro, dispararon, pero no hacia los policías, sino hacia arriba. Ahora que tratamos de explicar lo que pasó, pensamos que es posible que estos hombres eran unos infiltrados y provocaron la balacera. No, no eran de nuestra organización, asegura Pablo Mayo". 
El locutor-mediador en $\mathrm{J}$ ofrece detalles, en voz del sobreviviente, sobre la matanza (cfr. J30/6-1,18); el tópico principal de la noticia es el relato de los sobrevivientes, que sostiene cómo los policías fueron quienes comenzaron. El principal valor de análisis es que al identificarse el SE con los informantes, puede constituir prácticamente la hipótesis del SE. El mediador asume en OQO su función de locutor-narrador; despoja el relato del sobreviviente para identificarse con él mediante mecanismos de narrativización. El locutor-mediador se apropia del discurso e introduce al sobreviviente en sus términos.

En el caso de U, se incluye la voz de los sobreviviente solamente en la noticia generadora (a diferencia de $\mathrm{J}$, donde es posible hallar otras noticias en el MR), con distintas estrategias de caracterización en la inserción del enunciador en el discurso; la primera de ellas es su condición de heridos desde el hospital. El sobreviviente no presenta estados pasionales, éste es un informante herido, con algunas huellas ("fractura de fémur"). Las "proposiciones locales" de estos relatos son: a) la dificultad para el auxilio médico; b) los primeros en disparar fueron los policías. El entorno médico permite la decodificación del dolor. Más que un relato de la experiencia médica que justifica la mirada del SE, en el párrafo 16, es la voz del médico del hospital la que enlista todos los heridos. El informante es el médico, no el SE como en el caso de J ( $R$ no los señala).

La ausencia del sobreviviente en el MR no puede ser algo causal, reducido a las explicaciones de los propios mecanismos de la producción de la noticia, esta ausencia cumple un valor. Todo MR es, como el discurso mismo, un proceso de selección temática. La ausencia de la voz del sobreviviente en la conformación del MR nos parece una valoración no explicada únicamente por ciertas cuestiones técnicas, como el acceso a la fuentes. La presencia (o ausencia) de informantes obedece también a los intereses del mediador en la construcción del relato noticioso.

\section{La instancia agresora en la noticia generadora}

A diferencia de la caracterización personalizada que $\mathrm{J}$ realiza de los campesinos, la estrategia general de presentación de la autoridad es la despersonalización. La autoridad se cita por instancias inanimadas (un boletín o un diario que $J$ califica de oficialista).

Cuando J habla de "versión oficial" engloba dos dimensiones de la "voz oficial": el director de la policía y la principal fuente oficial de toda la nota, que es el boletín de PJE. La NG incluye párrafos donde encontramos la voz de la autoridad despersonalizada (cfr. J29/6,1-18 párrafos7-10) y distante ("El boletín dice que el director informó...”). En el párrafo 10 el lector se encuen- 
tra con una referencia institucional ("El director de la judicial afirmó que...") que no procede de una voz personalizada, sino de un "boletín oficial del gobierno del estado". El SE ha "antropomorfizado" al boletín y ha distanciado la voz del sujeto real en la versión oficial. El único acercamiento personalizado que tenemos en $\mathrm{J}$ de la autoridad es a través del RS, quien presenta al otro (la autoridad) como quien se burla de la propia situación. ${ }^{19}$

U personaliza la voz de la autoridad que precisa más detalles de los hechos. A diferencia del RS, las versiones transcritas de la autoridad provienen de un texto ya formulado (informe, boletín). Mientras que los sobrevivientes realizan operaciones sucesivas para entender qué y por qué pasó, las versiones de la autoridad (Godoy Figueroa) presentan una visión más estructurada y organizada de los hechos en el que los actores, las acciones y las causas son muy claros. No es casual que la fuente enunciadora (el documento de la autoridad) "afirme", "asegure".

En $\mathrm{R}$ tampoco aparece la autoridad personalizada. En el segundo párrafo, la información oficial aparece confrontada con la versión del PRD. Al final de la noticia tenemos una cita indirecta que presenta un listado de armas. ${ }^{20}$ La enumeración es la expresión rápida de una serie de ideas sobre el mismo asunto. Enumerar, más que dar detalle de los contenidos, es una categoría que agrupa el sema "violencia". La autoridad, al enlistar, aparece en la construcción de entidad objetiva que recaba información y de la cual el locutor-mediador no realiza juicio alguno. Ahora bien: el texto no específica el propietario de las armas, al provenir de la fuente oficial (la procuraduría estatal, que no la policía; es decir, una instancia investigadora) puede atribuirse como elemento a favor del argumento oficial: el hecho de $A B$ como producto de un enfrentamiento.

En su conjunto, podemos afirmar que el represor directo no aparece (lo que, de hecho, será una constante en todo el MR); tenemos informaciones indirectas sobre él mediante instancias, boletines, formatos, pero no hay un discurso en ED. Lo sabremos más adelante en el MR, a través de los policías detenidos. Esta "ausencia" se debe a que éste no quiere o no puede mostrarse. Las acciones de la autoridad (sobre todo de la Policía Judicial, como veremos en el siguiente inciso) son básicamente dar versiones de los hechos, listado de

19. Como lo leemos en este fragmento de la versión que Apolonio Romero (informante principal de J) da de los hechos (cfr. J29/12-1,18): (19) “Los policías dijeron: eso les pasa por mitoteros; mejor se hubieran quedado a sembrar su maíz y no les pasaba esto. $Y$ diciendo esto, a las personas que se encontraban heridas, las acababan de matar".

20. Cfr. R29/6-1,1A: (7) "La Procuraduría estatal informó que en lugar de los hechos fueron encontraron un rifle AK-47 o 'cuerno de chivo', abastecido con 20 tiros; una escopeta Thompson calibre 12; una pistola Colt calibre .38 súper; otra .45 ; una calibre .9 milímetros, y una .25 , así como un rifle calibre .22". (8) "Asimismo se recogieron 6 cascajos calibre .45 , cuatro cascajos de una AK-47, 12 cascajos .9 milímetros y dos más .38 súper, señaló en el comunicado". 
armas, confrontar versión con los agredidos. La autoridad aparece en su rol asertivo, más que ejecutivo (al menos en la noticia generadora). Sabemos de ellas por versiones, por partes.

\section{Distribución de las metaestructuras en el cuerpo de la noticia}

La macroestructura de un texto es una representación abstracta del mismo que tiende a la aprehensión total de su significado. Se fundamenta en las relaciones existentes entre los diversos elementos que constituyen dicha macroestructura. Un análisis global del texto transmitido mediante proposiciones locales demuestra que existe una coherencia interna que permite al lector entender el mensaje (Bueno, 2002). Toda noticia consta de dos partes claramente diferenciadas: encabezamiento y cuerpo de la noticia.

En los tres medios señalamos distintos procedimientos en la construcción de la NG de AB. Ya hemos hecho comentarios al encabezamiento y la entrada: $\mathrm{J}$ ofrece la noticia más extensa, con más información y más actos de habla que rebasan las funciones estrictamente referenciales e informativas. En los 38 párrafos del texto, después del resumen inicial se incluyen detalles en la confrontación de versiones, destaca el rol narrador que asume el mediador y el mayor espacio que da a los sobrevivientes e instancia agredida. La construcción del texto incluye elementos metaestructurales - señalados por Van Dijk (1990) - como el "contexto" o los "datos secundarios" que no aparecen en R. $\mathrm{U}$ presenta una noticia que ofrece algunos detalles secundarios, pero que en cambio no incluye antecedentes ni remite a hechos previos que abran la interpretación de la noticia al ámbito de un conflicto más amplio y extenso. Si consideramos la distribución de las "proposiciones locales" y las metaestructuras, podemos deducir el siguiente cuadro. 


\begin{tabular}{|c|c|c|c|}
\hline Metaestructuras & La Jornada & El Universal & Reforma \\
\hline Situación & $\begin{array}{l}\text { Acribillados campesinos por la } \\
\text { policia }\end{array}$ & \begin{tabular}{|l|} 
Mueren campesinos \\
producto de \\
enfrentamiento \\
ocss-policia \\
\end{tabular} & $\begin{array}{l}\text { Enfrentamiento } \\
\text { entre campesinos y } \\
\text { policias }\end{array}$ \\
\hline Comentarios & $\begin{array}{l}\text { Versiones encontradas } \\
\text { La policia se burla, llama a los } \\
\text { campesinos "mitoteros" }\end{array}$ & \begin{tabular}{|l|} 
Militantes del PRD \\
rechazan "política \\
de sangre por parte \\
del gobierno" \\
\end{tabular} & Las partes difieren \\
\hline Antecedentes & $\begin{array}{l}\text { Organización de la matanza } \\
\text { desde el dia anterior; se narra } \\
\text { lo que los policias hicieron y } \\
\text { como prepararon la matanza. }\end{array}$ & (categoría vacía) & $\begin{array}{l}\text { Fecha de origen de } \\
\text { la ocss }\end{array}$ \\
\hline $\begin{array}{l}\text { Acontecimiento } \\
\text { principal }\end{array}$ & $\begin{array}{l}\text { La matanza del } 28 \text { a las 10: } 30 \\
\text { a. } \mathrm{m} \text {. }\end{array}$ & $\begin{array}{l}\text { La matanza fue al } \\
\text { pasar el río Aguas } \\
\text { Blancas, a las } 10 \text { : } \\
00\end{array}$ & $\begin{array}{l}\text { La contraposición } \\
\text { informativa }\end{array}$ \\
\hline Secuencia & $\begin{array}{l}\text { El mediador alterna versiones } \\
\text { de los sobrevivientes y de la } \\
\text { autoridad. } \\
\text { Contexto de formación ocss } \\
\text { Relato de la preparación de la } \\
\text { matanza el dia } 27 \text { de junio. } \\
\text { Conferencia de prensa la } \\
\text { noche del } 28 \text { de junio del PRD. } \\
\text { Se da a conocer listado de } \\
\text { heridos y muertos. } \\
\text { Reacciones de una legisladora } \\
\text { del PRD en la ciudad de México. }\end{array}$ & $\begin{array}{l}\text { Declaraciones del } \\
\text { PRD sobre el saldo } \\
\text { del hecho } \\
\text { Plantón de } \\
\text { militantes del PRD. } \\
\text { Relatos de testigo. } \\
\text { Declaración a la } \\
\text { prensa del director } \\
\text { del hospital en } \\
\text { Acapulco. } \\
\text { Acude MP al lugar } \\
\text { de los hechos y } \\
\text { toma declaración. } \\
\text { Detención del lider } \\
\text { local del PRD } \\
\end{array}$ & $\begin{array}{l}\text { Lider del PRD en } \\
\text { Coyuca calcula en } \\
14 \text { el número de } \\
\text { muertos. Narra. } \\
\text { Dato de contexto } \\
\text { Informe de la PRD y } \\
\text { parte del listado de } \\
\text { armas encontrado } \\
\text { en el lugar. }\end{array}$ \\
\hline $\begin{array}{l}\text { Contexto } \\
\text { (circunstancias y } \\
\text { acontecimientos } \\
\text { previos) }\end{array}$ & $\begin{array}{l}\text { Formación de la ocss, sus } \\
\text { primeras movilizaciones }\end{array}$ & (categoría vacia) & $\begin{array}{l}\text { Fecha del } \\
\text { surgimiento de la } \\
\text { ocss y acción } \\
\text { anterior } \\
\end{array}$ \\
\hline $\begin{array}{l}\text { Conclusiones } \\
\text { (expectativas / } \\
\text { evaluaciones) }\end{array}$ & Nacionalización del hecho & $\begin{array}{l}\text { Amenazas a los } \\
\text { lideres del PRD por } \\
\text { parte de la } \\
\text { autoridad. }\end{array}$ & (categoria vacia) \\
\hline
\end{tabular}

En cuanto a los tópicos que aparecen en las noticias, y después de aplicar las macrorreglas de Van Dick a las noticias generadoras, éstos son: 


\begin{tabular}{|c|c|c|}
\hline La Jornada & El Universal & Reforma \\
\hline $\begin{array}{l}\text { 1) Campesinos de Guerrero } \\
\text { mueren al ser acribillados por } \\
\text { la policía del estado. } \\
\text { 2) La versión de los } \\
\text { sobrevivientes es que ellos no } \\
\text { llevaban armas y que los } \\
\text { policias fueron los atacantes, } \\
\text { especialmente con los de la } \\
\text { OCSS, quienes se dirigian a } \\
\text { una manifestación; la versión } \\
\text { del gobierno estatal es que los } \\
\text { campesinos agredieron a los } \\
\text { policias a balazos cuando } \\
\text { éstos realizaban un retén de } \\
\text { seguridad. } \\
\text { 3) El PRD culpa al gobierno de } \\
\text { Guerrero del asesinato de los } \\
\text { campesinos. }\end{array}$ & $\begin{array}{l}\text { 1) Dirigentes perredistas, } \\
\text { campesinos y el gobierno } \\
\text { estatal tienen versiones } \\
\text { distintas sobre los } \\
\text { acontecimientos en Coyuca. } \\
\text { 2) Militantes del PRD dicen } \\
\text { rechazar "la política de sangre" } \\
\text { de Guerrero en el plantón que } \\
\text { realizan frente al palacio } \\
\text { municipal. }\end{array}$ & $\begin{array}{l}\text { 1) Campesinos y policias se } \\
\text { enfrentan en Coyuca y cada } \\
\text { parte difiere en información. }\end{array}$ \\
\hline
\end{tabular}

Vemos como $\mathrm{J}$ incluye un mayor número de tópicos, no hay identificación con la autoridad, con la que marca una distancia, al grado que cuando se "acerca" a ella lo hace mediante la voz del sobreviviente. Por su parte, en U observamos una "perredización" de la noticia que lleva a ubicar a este actor como principal dentro del texto; de hecho, los agredidos son caracterizados principalmente como militantes perredistas. En $\mathrm{R}$, el texto queda reducido al esquema básicos y los componentes mínimos en que los actores del conflicto aparecen en una cierta simetría (se enfrentan), la cual se reproduce como hemos mencionado en el texto. Lejos de un mayor o menor acercamiento a algunos de los polos en el eje de la agresión, observamos una tendencia genérica a la síntesis de sus componentes en una construcción mucho menos compleja.

\section{Algunas observaciones finales}

En esta porción de nuestro análisis hemos querido mostrar algunos de los conceptos presentados en la primera parte del trabajo. Nuestro análisis sigue la concepción de que analizar un texto no es devolver el texto a su individualidad, sino a su juego (Barthes, 1980).

Al observar las NG, J en su conjunto presenta un estilo más libre en el manejo de los datos mediante estructuras citacionales más complejas y varia- 
das; por su parte, $\mathrm{R}$ usa estilos de citaciones dentro de la tradición más informativa (brevedad, sencillez, etcétera). $U$ abre el espacio de la confrontación, convoca a varias voces, diferencia un poco más la instancia reprimida y represora, pero, salvo algún párrafo, no alcanza el nivel de complejidad en la estructura citacional; es, en ese sentido, el medio más ambiguo entre la instrucción de lectura del titular de la noticia y su resolución en el texto. El texto de $\mathrm{U}$ no tiene la simplicidad estilística de $\mathrm{R}$, pero tampoco la complejidad enunciativa de $J$. $R$ nos deja ver una imagen del SE como un representador "liberal" que da equidad (dentro de su brevedad) a las fuentes informativas de que dispone; esta estructura es anunciada desde la misma ventana de la noticia en R, el marcador "Cuando menos" que abre la entrada de la noticia no cumple solamente una función de "ventana", es un aviso sobre la estructura enunciativa que nos encontraremos a lo largo de la noticia. A $\mathrm{J}$ no le preocupa esa "equidad" en la distribución de la información; realiza un mayor esfuerzo en la figurativización del agredido como sujeto de la agresión; vemos en $\mathbf{J}$ una mucho mayor cercanía enunciativa con el agredido y confrontación con la autoridad. Al ser el diario que mayor superficie dispone para la noticia generadora, la organización textual incluye marcadores narrativos gracias a los cuales distribuye las variadas acciones citadas y referidas.

La teoría de la enunciación (Maingueneau, 1976) tiene por objetivo mostrarnos la distancia enunciativa, la modalización y la opacidad o transparencia. En ese sentido, vemos en $J$ la tendencia al mayor acercamiento, pero el locutor-mediador se atribuye el trastocamiento a través de estilos discursivos más libres (OQO). En el otro extremo, $R$ acude a una mayor distancia enunciativa a través de estilos canónicos y la ausencia de determinada información. Esta "distancia" se vincula con la modalización más marcada que el locutor-mediador realiza de los actores a través de los procesos citacionales, y las estrategias discursivas de temporalización, espacialización y figurativización.

Hemos mostrado la complejidad que puede asumir el discurso informativo de DH. Pensamos que, al margen de la descripción socio-semiótica, el conocimiento de los mecanismos de uso en estos discursos puede ayudar a una defensa más integral que desmitifique, por una parte, cualquier discurso grandilocuente (de la sociedad política, de los medios masivos e incluso de las propias organizaciones civiles). Nuestra propuesta de estudio del discurso informativo integra a una visión más amplia de los DH desde una epistemología comunicativa, que precisa la operaciones mediacionales que realizan los medios como entidades constructoras del acontecer público. 


\section{Bibliografía}

Abril, Gonzalo (1995), "Análisis semiótico del discurso", en Delgado, Juan Manuel y Juan Gutiérrez, Métodos y técnicas cualitativas de investigación en ciencias sociales, Madrid, Síntesis-Psicología, pp. 427-463.

Anscombre, Jean Claude y Oswald Ducrot (1994), La argumentación en la lengua, Madrid, Gredos [ $1^{\mathrm{a}}$ ed. en francés, 1988

Barthes, Roland (1980), $S / Z$, México, Siglo XXI [1 ${ }^{\text {a }}$ ed. en francés, 1970].

Beristáin, Helena (2000), Diccionario de retórica y poética, Porrúa ( $8^{\mathrm{a}} \mathrm{ed}$.), México [1 $1^{\mathbf{a}}$ ed. en inglés, 1985].

Bueno Lajusticia, Ma. Rosario (2002), "Estructura textual, macroestructura semántica y superestructura formal de la noticia", en Revista Electrónica Mensaje Periodístico, Madrid, núm. 6, UCM. En línea, disponible en: www.ucm.es/info/Period_I/EMP/Numer_06.htm

Calsamiglia, Helena y Amparo Tusón (1999), Las cosas del decir. Manual de análisis del discurso, Barcelona, Ariel.

Cervini, María Cecilia, Nélida Sosa y Alicia Bosani (2000), Análisis lingüístico del discurso de la prensa. Consultado el 28 de marzo de 2000, disponible en: http://www.geocities.com /ColleguePark/5025/mesa4b.htm

Cohen, Stanley (1995), Denial and Acknowledgement: The Impact of Information about Human Rights Violations, Londres-Jerusalén, Center for Human Rights-The Hebrew University of Jerusalem.

Escandall Vidal, Ma. Victoria (1993), Introducción a la pragmática, Barcelona, UNED-Anthropos.

Ferrari, Laura y Susana Gallardo (1999), "Los marcadores de evidencialidad empleados por la prensa en una controversia ambiental", en Discurso y Sociedad, Barcelona, Gedisa, vol. 1, núm.4, pp. 69-93.

Fernández, Lagunilla y Covadonga Pendones (1997), "Discurso periodístico y juegos de palabras en los títulos de prensa", en Discurso. Teoría y análisis, UNAM-CCH, núm. 21/22, pp. 77-102.

Giménez, Gilberto (1983), Poder, Estado y discurso, México, UNAM.

González Reina, Susana (1994), "La significación de la realidad en la construcción del discurso periodístico", en Revista Mexicana de Ciencias Políticas y Sociales, México, UNAM, núm. 155, año XXXIX (nueva época). (2002), "El discurso periodístico como esquematización", en Maldonado, Patricia (coord.), Horizontes comunicativos en México. Estudios críti$\cos$, México, Asociación Mexicana de Investigadores de la Comunicación (AMIC), pp. 247-268. 
Greimas, A. J. y J. Courtés (1990), Semiótica. Diccionario razonado de la teoria del lenguaje, Madrid, Gredos, t. I [1 ${ }^{\mathrm{a}}$ ed. en francés, 1979].

Gutiérrez, Silvia (1989), Notas sobre las técnicas del análisis del discurso. Módulo de Técnicas para el análisis del discurso del diplomado Análisis Político de la Información, Centro Avanzado de Comunicación, México. Haidar, Julieta (1998), “Análisis del discurso", en Galindo Cáceres, Jesús (coord.), Técnicas de investigación en sociedad, cultura y comunicación, México, Conaculta-Addison Wesley Longman.

Imbert, Gérard y José Vidal Beneyto (coords.) (1986), "El País" o la referencia dominante, Barcelona, Mitre.

López García, Ángel (1996), Escritura e información. La estructura del lenguaje periodístico, Madrid, Cátedra.

Lozano, Jorge, Cristina Peña-Marín y Gonzalo Abril (1997), El análisis del discurso. Hacia una semiótica de la interacción textual, Madrid, Cátedra.

Maingueneau, Dominique (1976), Introducción a los métodos de análisis del discurso, problemas y perspectivas, Buenos Aires, Hachette.

- (1996), Términos claves del análisis del discurso, Buenos Aires, Nueva Visión.

Martínez Vizcarrondo, Doris (1998), El discurso periodístico sobre la guerra en el Golfo Pérsico: un análisis crítico. Tesis Doctoral no publicada. Universidad Autónoma de Madrid, Facultad de Filosofía y letras. Departamento de Lógica, Lingüística, Lenguas Modernas y Filosofía de la Ciencia.

Peña-Marín, Cristina (1997), "El análisis de textos en una nueva clave. Discursos e imágenes sobre la inmigración en El País", en Cuadernos de Información y Comunicación, Madrid, Servicio de Publicaciones, UCM, núm. 3, pp. 145-166.

Poloniato, Alicia y Lourdes Rodríguez (1987), Mirando el poder. Análisis del discurso político y social, México, UAM-Xochimilco-Plaza y Valdés.

Prieto, Daniel (1986), La fiesta del lenguaje, México, UAM-Xochimilco.

Reyes, Graciela (1984), Polifonía textual. La citación en el relato literario, Madrid, Gredos.

Rodrigo Alsina, Miquel (1989), La construcción de la noticia, Barcelona, Paidós-Comunicación.

Romero Álvarez, María de Lourdes (1996), "El relato periodístico como acto de habla", en Revista Mexicana de Ciencias Políticas y Sociales, México, Facultad de Ciencias Políticas y Sociales-UnAM, núm. 165, año XLI.

Sosa, Nélida Beatriz (2000), "Estrategias retóricas en la construcción de la actualidad periodística. Análisis de la noticia de la prensa", en Gimate- 
Welsh, Adrián (comp.), Ensayos semióticos: dominios, modelos y miradas desde el cruce de la naturaleza y la cultura, México, Asociación Mexicana de Estudios Semióticos-Porrúa, pp. 107-115.

Van Dick, Teun A. (1978), La ciencia del texto, Barcelona, Paidós.

(1990), La noticia como discurso. Comprensión, estructura y producción de la información, Barcelona, Paidós.

(1998), Estructuras y funciones del discurso, México, Siglo XXI $\left(12^{\mathrm{a}} \mathrm{ed}.\right)\left[1^{\mathrm{a}} \mathrm{ed}\right.$. 1980]. 